\title{
Os desafios e as possibilidades do trabalho docente com o aluno surdo na universidade
}

\author{
Flavinês Rebolo \\ Nayara Cesário Martins
}

Resumo: O artigo apresenta um estudo que objetivou analisar o trabalho docente frente aos processos de inclusão e de ensino e aprendizagem do aluno surdo na universidade, identificando os desafios enfrentados e as práticas utilizadas pelos professores. A pesquisa, de abordagem qualitativa, utilizou como instrumento para coleta de dados a entrevista semiestruturada. Participaram 16 professores dos cursos de licenciaturas, que ministravam aulas para alunos surdos, em uma universidade de Campo Grande/MS. Para as análises utilizou-se a análise temática de conteúdo de Schütze. Os resultados apontam que os principais desafios enfrentados pelos professores dizem respeito ao planejamento e preparação das aulas com materiais pedagógicos diferenciados, à avaliação dos alunos surdos e à relação com os intérpretes da Língua Brasileira de Sinais. Também foi possível identificar experiências de mal-estar, vividas por esses docentes, por não conhecerem a Libras e por não conseguirem participar diretamente dos diálogos com os alunos surdos.

Palavras-chave: Trabalho docente. Aluno surdo. Professor universitário.

\section{The challenges and possibilities of teaching work with the deaf student at the university}

\begin{abstract}
The article presents a study that objected to analyze the teaching work in the processes of inclusion and teaching and learning of the deaf student in the university, identifying the challenges and the practices used by the professors. The research, of qualitative approach, used as instrument for data collection the semistructured interview. Participants were 16 professors from the undergraduate courses, who taught classes for deaf students, at a university in Campo Grande / MS. The thematic analysis of content, of Schütze, was used for the analyzes. The results point out that the main challenges faced by professors are related to the planning and preparation of classes with differentiated teaching materials, to the evaluation of deaf students and to the relation with the interpreters of the Brazilian Language of Signals. It was also possible to identify experiences of malaise experienced by these professors, for not knowing the Libras and for not being able to participate directly in the dialogues with the deaf students.
\end{abstract}

Keywords: Teaching work. Deaf student. University professor. 
REBOLO, Flavinês; MARTINS, Nayara Cesário. Os desafios e as possibilidades do trabalho docente com o aluno surdo na universidade.

\section{Introdução}

Ainda são escassos os estudos com foco na inclusão de surdos na universidade, segundo Santana (2016), e isto se deve, provavelmente, ao fato de que o acesso e a presença desses estudantes no ensino superior é algo bastante recente na maioria das universidades brasileiras. Percebe-se, no entanto, que cada vez mais os alunos surdos estão avançando em sua caminhada escolar e chegando ao ensino superior, com maiores oportunidades em diversos cursos (SANTANA, 2016; BISOL et al., 2010).

$\mathrm{Na}$ universidade, os professores enfrentam vários desafios relacionados à inclusão do aluno surdo, como, por exemplo, as questões implicadas na relação professor/aluno surdo durante as aulas e professor/intérprete de Língua Brasileira de Sinais (Libras), além dos desafios concernentes às práticas pedagógicas necessárias ao aprendizado dos conteúdos pelo aluno surdo.

Como uma primeira aproximação desta realidade, o estudo realizado visou analisar o trabalho docente no processo de ensino e aprendizado do aluno surdo na universidade. Por meio de entrevistas semiestruturadas, foram entrevistados 16 professores de uma universidade de Campo Grande, MS, que tinham alunos surdos incluídos em suas turmas dos cursos de licenciatura em Biologia, Educação Física e Pedagogia. As entrevistas foram registradas com gravador de áudio, transcritas na íntegra e analisadas em conformidade com o modelo de análise temática de conteúdo, proposto por Schütze (2010a, 2010b, 2014).

Os 16 professores participantes da pesquisa têm idade entre 33 e 64 anos; cinco são homens e onze mulheres. Quanto à formação, três são graduadas em Pedagogia, dois em Ciências Biológicas, dois em Fisioterapia, dois em Matemática, dois em Psicologia, dois em Educação Física, um em História e um em Jornalismo. Desses docentes, onze possuem especialização em suas áreas de formação, todos têm mestrado e três são doutores. A jornada de trabalho varia de 40 horas/aulas semanais (onze professores) a 17 horas/aulas semanais (cinco professores). Todos atuam como docentes na educação superior há pelo menos cinco anos e dois professores têm carreiras mais longas, com 34 anos na docência universitária. Sete professores já haviam trabalhado com alunos surdos no ensino superior e os outros nove estavam vivenciando, no momento desta pesquisa, a primeira experiência como professores de alunos surdos.

Os resultados apresentados a seguir mostram os desafios que esses professores enfrentaram em sala de aula para a inclusão do aluno surdo, as práticas pedagógicas adotadas e 
REBOLO, Flavinês; MARTINS, Nayara Cesário. Os desafios e as possibilidades do trabalho docente com o aluno surdo na universidade.

algumas especificidades das relações entre o professor e o aluno surdo e entre o professor e o intérprete educacional.

\section{O trabalho do professor e o aluno surdo na universidade}

O trabalho docente é instituído pela finalidade da ação de ensinar e, segundo Basso (1998), o professor é o agente mediador entre o processo de apropriação do conhecimento pelo acadêmico e os sentidos de um conjunto de saberes que são efetivados por meio de determinadas práticas didático-pedagógicas. Essas práticas, muitas vezes, não são suficientes e/ou adequadas para atender às necessidades impostas pelas transformações sociais e tecnológicas do nosso século, impondo grandes desafios e exigindo, do professor e das instituições, constantes esforços de atualização e mudanças, para que se criem ações inclusivas e planejamento adequado de práticas pedagógicas que favoreçam a aprendizagem e atendam às necessidades de todos os alunos durante sua permanência na educação superior.

Um desses desafios, que será analisado aqui mais detalhadamente, está colocado com a presença de alunos surdos na universidade, que começou a se intensificar com a Lei 10.436, de 24 de abril de 2002 (BRASIL, 2002), que dispõe sobre a Língua Brasileira de Sinais (Libras), e com o Decreto 5.626 (BRASIL, 2005) que garante o direito à educação das pessoas surdas ou com deficiência auditiva.

Os surdos fazem parte de um grupo que necessita de atendimento educacional especial, principalmente por não conseguirem se comunicar por meio da oralidade e por possuírem a Libras como primeira língua. A Lei 10.436 (BRASIL, 2002) garante a presença de um agente facilitador, ou de apoio, que é o intérprete de Libras na sala de aula, mas Moura (2000) enfatiza a importância do professor também conhecer a Libras, a fim de que a responsabilidade pela comunicação e pelo ensino dos alunos surdos não recaia somente sobre o intérprete.

Além disto, se considerarmos a inclusão com um sentido mais amplo, que é o estar com o outro, é aprender a viver com o outro, é a participação das pessoas em uma nova e enriquecedora proposta educacional que celebra a diversidade e as diferenças, conforme afirma Aranha (2001), o papel do professor vai muito além do conhecimento da Libras. Segundo Lima (2015), a inclusão dos surdos na sala de aula não deve ser pautada apenas na interação física, mas também, na troca de conhecimentos, interações socioculturais e formação compartilhada. 
O grupo de alunos surdos busca uma educação que respeite a sua diferença. De acordo com Stumpf (2008, p. 23), “os movimentos surdos apontam para a construção de outra história para sua educação, uma história que não a da falta. Temos sugerido caminhos e mostrado que recursos sociais e artefatos culturais podem tornar à surdez aquilo que ela realmente é: uma diferença a ser respeitada".

$\mathrm{O}$ apoio pedagógico diversificado é considerado um mediador da aprendizagem e do desenvolvimento desses alunos e é mais eficiente do que um trabalho segregado, com programações específicas. Esse tipo de trabalho, evidentemente, traz grandes desafios às instituições de ensino e aos professores, no sentido de desenvolver e oferecer recursos diferenciados e metodologias de ensino que assegurem o êxito na tarefa de atender o aluno surdo e atingir os objetivos curriculares. Assim, além dos desafios cotidianos, quando se tem alunos surdos na classe, o professor universitário também enfrentará o desafio de preparar uma metodologia diferenciada, o que exigirá esforço extra desses professores. Enfrentar esses desafios exigirá conhecimento, não apenas técnico-científico, mas também, de recursos emocionais e estratégias de enfrentamento para superar as dificuldades.

O professor necessita realizar um esforço comportamental e cognitivo, precisa saber lidar com as dificuldades apresentadas, assim como com as demais pessoas e o meio. É importante salientar que o professor precisa buscar estratégias de enfrentamento para minimizar ou solucionar suas dificuldades em sala de aula. Segundo França e Rodrigues (1997, p. 36), o enfrentamento é um "conjunto de esforços que uma pessoa desenvolve para manejar ou lidar com as solicitações externas ou internas, que são avaliadas por ela como excessivas ou acima de suas possibilidades". Quando desenvolvem um repertório de estratégias de enfrentamento, as pessoas podem se tornar mais capazes para lidar melhor com os obstáculos, escolhendo aquelas que podem ajudá-las a chegar a seus objetivos em diferentes situações. Nesse sentido é importante destacar o papel das formações continuadas, que devem não apenas oferecer conhecimentos técnicos disciplinares, e o apoio da instituição, tanto no que se refere às questões pedagógicas quanto às condições de trabalho adequadas.

O respeito pela diferença cultural e a percepção de que a educação precisa ter um olhar diferenciado para a diversidade em sala de aula são importantes para o processo educacional do surdo. Mesmo que se constitua um desafio para o professor, é fundamental buscar a igualdade de oportunidade em sala de aula a fim de que esse aluno e o professor atinjam seus objetivos, que é 
REBOLO, Flavinês; MARTINS, Nayara Cesário. Os desafios e as possibilidades do trabalho docente com o aluno surdo na universidade.

o aprendizado e, independentemente das experiências anteriores dos docentes, ser professor de surdo é desafiador, principalmente quando se trata de formação na educação superior.

Os professores entrevistados nesta pesquisa relataram vários desafios que tiveram de enfrentar ao ministrarem aulas em turmas com alunos surdos, entre eles: o planejamento e a preparação das aulas com materiais pedagógicos diferenciados, a avaliação dos alunos surdos, a relação com os intérpretes da Língua Brasileira de Sinais (Libras) e a falta de formação específica. Ao mesmo tempo relataram, também, as adaptações e modificações que fizeram em suas práticas com vistas a atender melhor o aluno surdo. A seguir são apresentados esses desafios e os modos encontrados pelos professores para enfrentá-los.

\section{Primeiro desafio: o planejamento, a preparação de materiais didáticos especiais e o ritmo das aulas}

Em relação ao planejamento, uma primeira dificuldade relatada pelos professores foi o fato de não terem sido avisados, com antecedência, da presença de um aluno surdo em suas turmas. Os professores, em geral, elaboram seus planejamentos antes do início do semestre a partir de um pressuposto de homogeneidade, para "alunos imaginariamente homogêneos", conforme afirmam Harriston e Nakasato (2015, p. 67). Se este pressuposto, de trabalhar o conteúdo de forma igual para todos, não atende completamente nem os alunos ouvintes, para o aluno surdo se torna ainda mais ineficiente. Nesse sentido, alguns dos professores entrevistados, ao se depararem com um aluno surdo na classe sentiram, de forma mais indubitável, a necessidade de um planejamento diferenciado.

Não sabia que teria um aluno surdo, para eu preparar melhor o conteúdo. (Profa. Paula) ${ }^{1}$

Não sabia que teria um aluno surdo. No início eu me dediquei mais. Precisei me organizar, não sabia como trabalhar com ele... (Prof. Bruno)

Não fui informada que teria um aluno surdo e tive que aprender como lidar com a situação. Às vezes, eu tinha planejado e precisava reorganizar. Precisei adaptar os vídeos, com legendas, adaptar os slides... os trabalhos eram mais individuais. (Profa. Deise)

\footnotetext{
${ }^{1}$ Os nomes de todos os professores participantes desta pesquisa foram substituídos por pseudônimos para garantia do anonimato.
} 
REBOLO, Flavinês; MARTINS, Nayara Cesário. Os desafios e as possibilidades do trabalho docente com o aluno surdo na universidade.

À surpresa de entrar em classe e se deparar com um aluno surdo soma-se, para esses professores, a percepção de que precisariam fazer adaptações em suas aulas, mas se sentiam despreparados, com conhecimentos insuficientes para realizar tais adaptações.

Faço meu planejamento e sempre procuro dar uma organizada, mas é complicado. Não recebi nenhuma orientação sobre como trabalhar com o surdo. Sinto que não pude ajudá-lo, fiquei frustrada. (Profa. Clara)

Eu demoro mais para preparar minha aula, porque preciso pensar no acadêmico e para facilitar a aprendizagem, uso recursos visuais... mas, eu percebo que ele tem dificuldade de compreensão de conceito, e eu não tenho muito conhecimento... (Profa. Bianca)

Assim, em relação ao planejamento e preparação das aulas e materiais pedagógicos diferenciados depreende-se, dos relatos de alguns dos professores, que estes se preocupavam em planejar as aulas, utilizando métodos que pudessem facilitar a compreensão dos conteúdos a serem ministrados e que possibilitassem a aprendizagem dos alunos surdos, mas percebe-se que a formação continuada, principalmente a específica para atender educandos com deficiência, deve ser oferecida pela instituição de forma sistematizada para maior eficiência e bem-estar dos professores. A Profa. Laura afirma que sentiu

Necessidade de formação continuada para atender meu aluno surdo, queria ter mais informação pedagógica, assim podemos melhorar o ensino e aprendizado do aluno surdo. $O$ desempenho dele foi ruim.

No caso da instituição estudada há um Núcleo de Apoio Pedagógico (NAP) e alguns professores o procuraram para obter subsídios para o planejamento, como relata a Profa. Eliane que, "além de buscar ajuda do NAP", também procurou "ler mais sobre o assunto por conta própria”, e o Prof. Bruno que "no começo não tinha segurança por falta de conhecimento e, ao longo do semestre, essa segurança foi construída... o NAP ajudou um pouco”.

Pode-se inferir que esses professores procuraram modificar ações, posturas e atitudes para atender às necessidades dos educandos com deficiência auditiva.

O trabalho docente de planejar e preparar aulas para turmas com alunos surdos despende muito tempo, pois é preciso buscar os recursos apropriados e diferenciados para trabalhar os conteúdos da aula. Segundo Harriston e Nakasato (2015), um texto escrito, por exemplo, para o surdo, é um recurso não construtivo, não acrescenta muito à explicação do professor, tendo-se em conta que a Língua Brasileira de Sinais, a primeira língua de um surdo, tem uma estrutura textual diferente da Língua Portuguesa, que é a sua segunda língua. 
REBOLO, Flavinês; MARTINS, Nayara Cesário. Os desafios e as possibilidades do trabalho docente com o aluno surdo na universidade.

Nesse sentido, o uso de imagens é fundamental em sala de aula, principalmente quando o professor está mediando o conhecimento para um aluno surdo. Mas é preciso, também, escolher material/imagens que estejam mais próximas da realidade desse aluno, para que ele consiga identificar e compreender o que está sendo lecionado.

Usei textos avulsos, slides eram com pequenos textos, imagens, filmes. Ele não precisou de tempo a mais para realizar, ele sempre participou de todas as atividades. A sala numerosa dificultou meu trabalho com acadêmico surdo. (Profa. Ana)

Utilizei alguns recursos em minhas aulas como slides bem coloridos, com figuras, muitas figuras e filmes e o meu jeito de ser bem articulada, dinâmica facilita bastante. (Profa. Clara)

No discurso dessas professoras constata-se que houve modificação no planejamento, incluindo a confecção dos slides com muitas imagens que poderiam facilitar o entendimento sobre conteúdos trabalhados em sala de aula. Com relação a esse recurso, Silva (1999, p. 487) observa que

Ao trazer a epistemologia visual para o campo pedagógico, os surdos, ao mesmo tempo que evidenciam as limitações do processo pedagógico centrado no som também apresentam a sua experiência visual como uma das alternativas possíveis para sua inserção e permanência no sistema de educação brasileiro (SILVA, 1999, p. 487).

A leitura de textos é um dos desafios para os alunos surdos, no seu processo acadêmico, uma vez que essas habilidades nem sempre foram/são trabalhadas de forma adequada, ao longo da trajetória escolar deles; sempre foi imposto o formato majoritário do ouvinte e não o bilinguismo no qual a Libras é a primeira língua e a Língua Portuguesa, a segunda língua. Karnopp (2013, p. 57) complementa afirmando que essa dificuldade acontece porque

na escola, busca-se uma correspondência estreita entre a Língua Portuguesa e a Língua de Sinais, subordinando os sinais à sintática do português, consequentemente sinais são inventados, a língua de sinas é artificializada e a escrita da portuguesa é imposta aos surdos sem considerar a diferença linguística e cultural.

Os textos, quando não adaptados às necessidades do aluno surdo, provavelmente não contribuem para uma aprendizagem efetiva, uma vez que as condições de compreensão do surdo são distintas das que têm os alunos ouvintes. Essa situação não deve ser encarada pelo viés da culpabilização, pois de acordo com Harriston e Nakasato (2015),

Devido ao histórico educacional e às dificuldades que enfrentaram e enfrentam para terem acesso às informações usualmente veiculadas através da audição, muitas vezes os surdos não conhecem os conceitos ligados às teorias, há palavras desconhecidas ou usadas em um contexto novo e/ou com outro sentido daquele que conhecem o que 
REBOLO, Flavinês; MARTINS, Nayara Cesário. Os desafios e as possibilidades do trabalho docente com o aluno surdo na universidade.

desestabiliza todos os conhecimentos até então adquiridos e a compreensão da matéria nova (p. 67).

As dificuldades relatadas pelos professores sobre a falta de conhecimento prévio desses alunos surdos em relação à fluência na leitura acontece. Os alunos chegam à universidade com lacunas no aprendizado devido ao processo de escolarização que não contemplou o bilinguismo nas escolas da Educação Básica, mas eles não podem ser responsabilizados por isso, tampouco colocados de lado; é preciso que os professores tenham uma postura coerente e trabalhem essas lacunas utilizando recursos diferenciados em sala de aula.

Além da preparação de material de apoio visual, outro aspecto destacado pelos professores foi o ritmo das aulas, o tempo necessário para a realização das atividades. Muitas vezes é necessário disponibilizar mais tempo para o aluno surdo desenvolver uma atividade de fixação, ou uma atividade avaliativa, uma vez que, dependendo do que lhe é solicitado e do grau de dificuldade para compreensão da Língua Portuguesa, o aluno surdo pode precisar de mais tempo para a realização da atividade.

Quando você elabora o planejamento, você não pensa que vai ter alunos diferentes. Eu quando explicava olhava para a intérprete, porque a comunicação é tudo, gesto, olhar. O ritmo de aula precisou diminuir. (Prof. Luan)

Tive que aprender a prestar atenção nas minhas aulas para atender o aluno. Mudar a minha aula, para atender a necessidade do aluno e modificar o ritmo da aula para o intérprete acompanhar explicação. Minhas dificuldades foram de conhecer o aluno e as necessidades dele. Tive Dificuldades em prestar atenção nos dois alunos surdos e intérprete ao mesmo tempo. (Profa. Julia)

Também se verificou na fala dos professores entrevistados que, em casos de necessidade, aceitavam receber os trabalhos e avaliações dos alunos surdos fora do prazo determinado para os alunos ouvintes. Os docentes compreendem que é preciso ficar atento o tempo todo em sua explicação do conteúdo, observando os alunos ouvintes, o intérprete educacional e o aluno surdo, principalmente com relação à leitura de suas expressões faciais e corporais que pode ser um indicativo de compreensão do conteúdo ministrado.

É de extrema importância que os professores reconheçam o surdo como sujeito diferente, que tem língua, cultura e identidade próprias e que tem o direito de receber subsídios e condições de igualdade de aprendizagem. É relevante que haja a inclusão dos surdos para o fortalecimento e relações culturais, tanto para os surdos como para os ouvintes. Nesse sentido pode-se dizer que a preparação do material de apoio visual, vídeos, adequação do ritmo da aula e a mudança de 
REBOLO, Flavinês; MARTINS, Nayara Cesário. Os desafios e as possibilidades do trabalho docente com o aluno surdo na universidade.

postura dos professores em classe são aspectos que refletem a preocupação dos professores com a aprendizagem desse alunado.

Mas, embora a maioria dos professores tenha se preocupado com as adaptações metodológicas de suas aulas houve, também, relatos de professores que não fizeram nenhuma adaptação, ou porque acreditavam que não havia necessidade ou por dificuldade em trabalhar com recursos visuais.

Acho que não tenho que tratar diferente, acho que tenho que colocá-lo na sala de aula em contato com os demais alunos e não tenho que modificar a sala por causa de só um aluno surdo, não pode tratá-lo como ser diferente de todo mundo e menosprezar a sala inteira só por causa desse aluno. (Prof. Fabio)

Na verdade, eu nunca mudei minhas aulas, porque a Filosofia é teórica, não tem como criar nada, é debate, leitura. Não sei se era a dificuldade de compreender a disciplina. Tem pessoas que não gostam... percebo que aconteceu com o acadêmico. A percepção que eu tinha era que se eu o tratasse diferente estaria considerando ele como coitado, incapaz. (Prof. Luan)

A forma como os surdos ainda são vistos por professores caracteriza um olhar clínicoterapêutico, ou seja, que os considera deficientes, "coitadinhos", que podem ter dificuldades de aprendizagem, razão por que, talvez, não modificam sua estratégia de ensino. Veja-se o que Lopes (1998, p. 114) escreve:

Os surdos, quando não representados como sujeitos culturais, entram no rol dos desajustados, desintegrados da sociedade ouvinte, deficientes e incapazes de se desenvolverem sem o auxílio de grupos dominantes culturalmente. A escola não pode mais representar e contar os sujeitos com os quais trabalha, referendada em um único modelo de normalidade ou deficiência. Ela precisa procurar vê-los dentro do hibridismo em que estão envolvidos enquanto sujeitos diferentes e pertencentes a um grupo cultural em permanente construção e desconstrução de conceitos, comportamentos, valores [...].

A percepção de que os surdos são deficientes e a concepção de planejamento hegemônico das aulas constituem embargos ao aprendizado desses alunos. Os relatos desses professores sugerem que estes não prepararam aula para atender o aluno surdo, não utilizaram métodos que pudessem facilitar o aprendizado desse aluno. Esse tipo de atitude aponta para a importância de uma formação continuada específica destinada a professores que têm de lidar com casos de alunos surdos, em suas aulas. A preparação do professor universitário para trabalhar com alunos surdos, assim como em qualquer outra área de atuação, é importante. Compreender a inclusão em todos os seus aspectos é imprescindível para a construção do plano de aula, estratégias de ensino e avaliação. 
REBOLO, Flavinês; MARTINS, Nayara Cesário. Os desafios e as possibilidades do trabalho docente com o aluno surdo na universidade.

A falta de preparação e o desconhecimento da Libras também afeta o desenvolvimento das aulas e as relações entre o professor e o aluno surdo.

Não tive formação para trabalhar com surdos. Compreender a Língua de Sinais é mais desafiador do que preparar a aula e fazer as adaptações necessárias. (Profa. Deise)

Não sabia a Língua de Sinais. O meu desafio era a preocupação em saber se a intérprete está entendendo, porque ela era minha fonte com o acadêmico... dependia dele para me comunicar com o aluno surdo. (Profa. Paula)

Nesse caso, a professora gostaria de ter recebido preparo para trabalhar com um aluno surdo. Os docentes devem participar de cursos de capacitação antes de entrar em sala de aula e se deparar com o desconhecido, com a escrita diferente, com a dificuldade de comunicação acarretada pela surdez do aluno. Os docentes devem receber subsídios que propiciem um olhar diferenciado, atento a todos os movimentos, uma sensibilidade à diferença e, também condições apropriadas de trabalho.

Tive dificuldade em saber se meu aluno surdo estava aprendendo o conteúdo. A sala era numerosa, isso dificultou um pouco para eu trabalhar com o acadêmico, não consegui dar atenção especial, não tinha tempo... Não tinha conhecimento se podia fazer avaliação diferente (Profa. Paula)

\section{Segundo desafio: a avaliação dos alunos surdos}

Os docentes têm autonomia para trabalhar a avaliação e, nas narrativas, observa-se que foram utilizadas diferentes formas de avaliar os alunos. Alguns professores avaliaram os alunos surdos da mesma forma que os alunos ouvintes; há os que realizaram alguma adaptação e outros procuraram avaliar o acadêmico de forma processual, durante o semestre, sem se prender apenas nas avaliações formais.

Professores que fizeram alguma adaptação no processo avaliativo, que sentiram a necessidade de avaliar o aluno surdo de forma diferenciada dos alunos ouvintes e utilizaram outros recursos de avaliação para acompanhar o aprendizado do conteúdo ministrado durante o semestre, relataram que

As avaliações eram simples, mas objetivas porque são licenciaturas gerais. Eu avalio a participação deles, não é só a prova. (Profa. Clara)

Nas avaliações precisei fazer uma adaptação na prova de exame. Eu conversei com ele sobre o conteúdo e pude avaliar a argumentação do conteúdo. As outras avaliações não foram adaptadas, foram às mesmas. (Profa. Paula) 
REBOLO, Flavinês; MARTINS, Nayara Cesário. Os desafios e as possibilidades do trabalho docente com o aluno surdo na universidade.

Alguns professores, ao avaliarem os alunos surdos preferiram fazê-lo durante o processo, ou seja, observando o desenvolvimento do acadêmico não só nas avaliações tradicionais, mas também em outros momentos de participação em sala de aula.

A avaliação com a acadêmica era uma cobrança mais suave na disciplina, avaliei o que ela produzia, não só o conteúdo, a avaliação foi adaptada sendo observada cada aula. (Prof. Yuri)

É preciso, no entanto, no que se refere às exigências de avaliação, dar condições de aprendizagem aos alunos surdos para que consigam ser avaliados com o mesmo rigor que os demais alunos da sala de aula. O professor Yuri, conforme se pôde observar, não tornou mais fácil o processo de avaliar o aluno surdo, apenas fez adaptações: avaliou a aluna ao longo do semestre e não apenas considerou as provas escritas, mas todo o processo.

Carvalho (2005, p. 58) faz referência a essas estratégias na educação superior:

[...] a grande marca do ensino superior não está em fazer benemerências ou atividades assistenciais, mas construir práticas pedagógicas que levem o aluno em formação a empenhar-se pelo bem comum, diagnosticar problemas e elaborar estratégias de intervenção viáveis no cenário em que atua.

Os professores participantes buscaram encontrar estratégias que pudessem auxiliar na avaliação do surdo. Em algumas narrativas percebe-se, ainda, que a avaliação não levou em conta apenas as respostas escritas, mas a forma como o aluno tinha compreendido o conteúdo e o apoio do intérprete educacional.

Alguns docentes revelaram que não fizeram adaptação nas avaliações durante o semestre, porém precisaram de auxílio do intérprete e de extensão do tempo para que os acadêmicos surdos realizassem as provas.

Precisei da presença do intérprete, para me auxiliar na compreensão da escrita... não tenho conhecimento da Libras. As dúvidas na prova ela perguntava para mim. A avaliação era a mesma. (Profa. Ana)

Dei um tempo maior para ele realizar a prova. O português dele era curioso, mas não precisei da ajuda do intérprete para corrigir. Sempre ficava ansioso para saber como foi o rendimento dele nas avaliações. (Prof. Bruno)

Alguns professores participantes estranharam o modo de escrever do aluno surdo. A professora Ana, por exemplo, necessitou do apoio do intérprete educacional para ajudá-la a corrigir a avaliação do seu aluno. A escrita do aluno surdo possui uma estrutura diferente por adotar a Libras como primeira língua, cuja característica espaço-visual foge dos padrões das 
REBOLO, Flavinês; MARTINS, Nayara Cesário. Os desafios e as possibilidades do trabalho docente com o aluno surdo na universidade.

línguas estrangeiras, inclusive da Língua Portuguesa, que é oral auditiva. Esta, para uma pessoa surda, constitui-se na segunda língua. Sendo assim, é compreensível que esses professores tivessem estranhado o modo de escrever de seu aluno surdo.

O tempo estendido para os alunos surdos realizarem a avaliação é também extremamente importante, quando o acadêmico necessita, além de ser também um direito garantido em legislação.

A professora Bianca declarou o seguinte posicionamento a respeito da presença do intérprete durante a avaliação e do atendimento às dificuldades com a Língua Portuguesa do aluno surdo:

Na avaliação, gosto que o acadêmico leia sozinho e, depois o intérprete vem interpretar o que ele não conseguiu compreender, aí sim o intérprete pode fazer a interpretação, pois acredito que o aluno precisa ter autonomia. (Profa. Bianca)

A preocupação da professora é com a autonomia do aluno, com seu aprendizado. Na visão dela, o aluno precisa tentar ler sozinho a avaliação e verificar o que é capaz de responder sem a tradução do intérprete. É possível, ainda, perceber que a professora não se posiciona contrária à presença do intérprete educacional durante a avaliação, tampouco proibiu o auxílio da tradução. A docente não demonstrou nenhuma inquietação em relação ao trabalho do intérprete na prova, mas defende que o aluno surdo tenha autonomia.

Foram utilizadas, ainda, outras experiências diversas de como avaliar o aluno surdo, conforme se pode ver nos relatos a seguir:

Eu usei dissertativa e discursiva aplico a mesma avaliação. Ele tem direto de ficar mais tempo. Ele nunca usou esse tempo extra. Se ele apresentou dificuldade, ele não falou ou pediu mais explicação. Ele faz a avaliação muito rápida e depois ele reclama que foi mal. (Profa. Eliane)

As avaliações, atividades avaliativas foram as mesmas. Eu acho que não teve as mesmas compreensões, acho que não ficou no mesmo nível ou aprendizado que os outros alunos. (Profa. Laura)

$\mathrm{Na}$ fala da professora Eliane, nota-se um desabafo sobre os desafios vivenciados com o acadêmico, apesar de lhe ter aplicado a mesma avaliação dos demais, com o tempo estendido para que tivesse tempo hábil para responder as questões avaliativas.

A professora Laura pontuou em seu excerto que o aluno surdo não aprendeu o suficiente, como os outros alunos. Essa preocupação remete ao que ela disse sobre seu planejamento: que faltou, ao acadêmico, o conhecimento prévio matemático e, a ela, a preparação de aula que pudesse facilitar o aprendizado a esse aluno. 
REBOLO, Flavinês; MARTINS, Nayara Cesário. Os desafios e as possibilidades do trabalho docente com o aluno surdo na universidade.

Para os professores deste estudo, os conhecimentos, habilidades e valores a serem alcançados pelos educandos com deficiência auditiva, incluídos nas turmas do ensino comum, devem ser os mesmos propostos para os seus colegas, variando, todavia, em relação ao apoio que esses alunos precisam receber, em função de suas peculiaridades, bem como em relação aos critérios de aquisição que forem mais convenientes para serem considerados nos processos de avaliação e, embora tenham feito adaptações em suas avaliações, deixaram claro esse posicionamento.

Mas para alguns professores, ao avaliarem o aluno surdo da mesma forma que os demais acadêmicos, foi necessário o apoio do intérprete educacional e, nesse sentido, manifestaram posicionamentos diferentes com relação à presença do intérprete durante avaliação:

Avaliei normalmente, e ele foi melhor que muitos alunos ouvintes, eu devo isso ao intérprete, ele não ia conseguir sozinho. (Prof. Fabio)

Com a intérprete na avaliação eu ficava com pé atrás, eu não sabia o que eles conversavam. Eu já perguntei para ela você não está respondendo pra ele não, né? Mas, ele foi claro dizendo que não, era dúvida em relação às palavras. Era de verdadeiro ou falso, era sempre o último a entregar. Não houve as adaptações. Ele ficou de exame, mas conseguiu ser aprovado. (Profa. Julia)

A avaliação eu ficava muito inseguro, porque eu não sabia o que estava acontecendo e pelo fato do intérprete saber o conteúdo não posso afirmar que ela ajudava ou não. (Prof. Luan)

Os diferentes posicionamentos dos professores em relação à presença e atuação do intérprete educacional, não só durante as avaliações, mas em todo o desenvolvimento das aulas, foi apontado pelos professores como outro grande desafio, que será discutido a seguir.

\section{Terceiro desafio: a relação com os intérpretes da Língua Brasileira de Sinais (Libras)}

A presença do intérprete de Libras é necessária e auxilia os professores na comunicação com os alunos surdos e, também, no apoio pedagógico. Alguns professores entrevistados se encantaram com o trabalho do intérprete, outros conseguiram fazer uma boa parceria com esse profissional e outros tiveram momentos conflituosos, fazendo referência a certo mal-estar relacionado à presença do intérprete na sala de aula.

Foi difícil no começo, até pra eu entender a função dele [intérprete]. Mas depois foi uma relação boa, afinal eu precisava dele.. (Profa. Kátia)

Intérprete é um agente facilitador, mas ainda é qualquer pessoa que quebra essa ideia de padronização na aula, ainda é um desconforto para os professores. (Profa. Inah) 
REBOLO, Flavinês; MARTINS, Nayara Cesário. Os desafios e as possibilidades do trabalho docente com o aluno surdo na universidade.

Os professores Bruno e Yuri ressaltam suas preocupações em relação ao acompanhamento do intérprete em suas explicações do conteúdo.

Preocupação de saber o que a intérprete está interpretando e como ela fazia... eu não entendia... eu queria falar com ele. (Prof. Bruno)

O intérprete está ali, ela [aluna surda] não está prestando atenção em mim... (Prof. Yuri)

Essas preocupações se devem, aparentemente, ao fato desses professores não terem conhecimento de Libras e, por essa razão, não compreenderem o que está sendo falado entre o intérprete e o aluno surdo. Além disso, se ressentiam por não conseguirem efetivar a comunicação com os alunos surdos e por não conseguirem obter suficientemente a atenção deles durante as explicações.

Albres (2015) aponta que o intérprete realiza suas práticas conforme lhe é permitido, porém o professor não tem clareza do papel desse profissional. Não saber falar em Libras, não ter acesso ao diálogo entre o intérprete educacional com o acadêmico surdo durante a avaliação são fatores que geraram mal-estar para alguns dos docentes deste estudo.

Os intérpretes foram os mediadores na comunicação e apoio para esses professores em sala de aula e, também, em relação às correções de prova e às informações sobre o aluno surdo. Para facilitar a compreensão do professor, o intérprete de Libras está sempre pronto a auxiliar com a tradução da escrita do aluno surdo. Essa confiança e apoio do intérprete para o professor é fundamental para que o trabalho pedagógico seja bem realizado e o aluno surdo seja avaliado adequadamente.

Ainda que a maioria dos professores entrevistados tenha relatado sobre as relações positivas que mantiveram com esses profissionais, existiram aqueles docentes que não se sentiam à vontade, em alguns momentos, com o trabalho do intérprete em sala de aula e, principalmente ao auxílio nas avaliações. O grande impasse era o receio de que o intérprete, mais do que apenas auxiliar no entendimento das questões da prova, desse as respostas ao acadêmico surdo.

Não tenho problema com o intérprete, preciso dele para trabalhar, trabalhamos bem. Mas não gosto que ele interpreta as avaliações. (Profa. Bianca)

Com a intérprete na avaliação eu ficava com pé atrás, eu não sabia o que eles conversavam. Eu já perguntei para ela: você não está respondendo pra ele não, né? Mas, ele foi claro dizendo que não, era dúvida em relação às palavras. (Profa. Julia) 
REBOLO, Flavinês; MARTINS, Nayara Cesário. Os desafios e as possibilidades do trabalho docente com o aluno surdo na universidade.

Na avaliação eu ficava muito inseguro, porque eu não sabia o que estava acontecendo e pelo fato do intérprete saber o conteúdo não posso afirmar se ela ajudava ou não. (Prof. Luan)

Em algumas narrativas pode-se perceber a preocupação dos professores com a atuação do interprete durante as avaliações. "Será que o aluno só foi aprovado por causa do intérprete? E a capacidade de aprender do aluno?” (Profa. Inah). Essas questões acerca do papel do intérprete precisam ficar claras para os docentes. Esse desconforto acontece porque se trata de um processo novo para vários professores. Muitos deles não tiveram capacitação, desconhecem o trabalho do intérprete educacional e vivenciam novo momento, sem compreender qual a melhor forma para trabalhar com os acadêmicos surdos e com os intérpretes.

Desse modo, a presença do intérprete, tanto na sala de aula como nas avaliações, ao mesmo tempo que é importante para o professor que não tem o domínio da Libras, também pode ser motivo de desconforto, pelo fato de não compreender os diálogos entre seus alunos e o intérprete, nas avaliações.

Tenho uma boa relação, às vezes eu assusto muito com as batidas de mão do intérprete na sala de aula. Eu preciso confiar que ela fazia esse trabalho da interpretação, mas, fielmente a minha fala, não posso afirmar, mas acho que ela passava o conteúdo. Se eu não confiasse, eu não conseguiria fazer minhas aulas, não vou conseguir aplicar prova porque vou achar que ela passa cola. Eu precisava ter essa confiança. (Profa. Clara)

A relação entre docente, alunos surdos e intérprete é de extrema importância ao bom andamento do processo de ensino e aprendizagem. Essa relação necessita de confiança, tanto do professor em relação ao trabalho do intérprete como do acadêmico surdo em relação ao intérprete educacional. Quanto mais harmonia houver entre os envolvidos, melhor será a relação destes em busca das adaptações necessárias para o aprendizado do aluno surdo.

Os relatos demonstram que cada um buscou uma forma própria de enfrentar as dificuldades, criando possibilidades de comunicação, de ensino e de inclusão.

O intérprete me auxiliou muito nas dúvidas que eu tinha sobre surdez, adaptando o material que era possivel. (Profa. Deise)

Evidencia-se que o intérprete é necessário para auxiliar o professor com 'dicas' de comunicação e, também, para sanar dificuldades em relação à própria aula; contudo, o professor não deve se prender somente a esse apoio de informações. É preciso ler sobre o assunto e buscar novas metodologias, para conseguir enfrentar outros desafios de ensino e melhorar o aprendizado do aluno surdo. 
Os docentes entrevistados tiveram seus enfrentamentos, ao longo do semestre, e buscaram possibilidades para atender às necessidades e especificidades do ensino ao acadêmico surdo e dar-lhe melhores condições de aprendizagem. Com relação ao convívio docente/intérprete, em sala de aula, foi possível perceber, nas falas dos professores participantes, que nem sempre a presença e ação do intérprete foi razão para o mal-estar docente; em muitas situações ambos mantiveram relação de pareceria na educação do surdo. Essa conduta é importante, pois o intérprete educacional tem um papel fundamental no processo educacional do surdo incluído em salas regulares.

\section{Considerações finais}

Com a intensificação do acesso dos surdos à universidade, novos desafios são colocados para os professores. Além de dar foco à inclusão e aos desafios e possibilidades de ensino do aluno surdo, a pesquisa apresentada teve o propósito de conhecer tais desafios e analisar as estratégias utilizadas pelos professores universitários para enfrentá-los, frente às especificidades do processo de ensino e de aprendizagem desse público. Também visou verificar as especificidades do relacionamento professor-aluno surdo e destes com o intérprete educacional, tendo em vista que essas interações são fatores decisivos para a aprendizagem.

Foram entrevistados 16 professores de uma Instituição de Ensino Superior (IES) de Campo Grande, MS, que ministravam aulas nos cursos de Licenciaturas e que tinham alunos surdos em suas turmas. Alguns destes professores afirmaram que já haviam trabalhado com acadêmicos surdos no ensino superior e outros estavam vivenciando a experiência pela primeira vez. Todos relataram desafios para realizar o trabalho docente, dentre os quais foram destacados, neste texto, o de elaborar e programar um plano de aula que pudesse favorecer o aprendizado do aluno surdo, o de realizar uma avaliação condizente e adequada e as relações com o intérprete de Libras.

As estratégias utilizadas pelos professores para trabalhar com aluno surdo constituíram um desafio, mas os docentes encontraram possibilidades para preparar aulas mais visuais, adaptar o ritmo das aulas e o tempo para as avaliações. Pesquisaram informações sobre a educação dos surdos, seja na literatura ou com o apoio do intérprete educacional e buscaram auxílio no Núcleo de Apoio Pedagógico (NAP) da IES. Os docentes buscaram formas de enfrentar seus desafios na 
inclusão do aluno surdo. A preocupação de compreender e ensinar esse aluno levou a maioria desses professores a criarem estratégias de ensino diferenciadas e isso foi importante tanto para o aluno surdo e como para eles próprios.

Ao analisar a fala dos professores em relação ao planejamento, verificou-se que a maioria procurou fazer adaptações em seus programas de ensino para melhor atender os alunos surdos; mas alguns docentes afirmaram não terem feito modificações por acreditarem que todos aprendem da mesma maneira, a partir dos mesmos referenciais, e porque as dificuldades não são exclusivas do aluno surdo, mas também são dos alunos ouvintes.

A maioria dos docentes utilizou recursos visuais para facilitar a aprendizagem dos alunos surdos, alguns dedicaram longo tempo ao preparo do material e alguns nem tentaram a utilização de recursos diferenciados, ou porque não sabiam se era necessário ou porque não sabiam como fazê-lo.

Com respeito à avaliação, embora muitos docentes não tenham feito adaptações em suas provas, alguns atribuíram maior valor ao processo de ensino e de aprendizagem desses alunos surdos para computar a avaliação final. A avaliação da aprendizagem desses alunos ocorreu concomitante à dos alunos ouvintes, tanto nas provas como nos exames finais.

Outro grande desafio enfrentado pelos professores com o aluno surdo em classe foi o da comunicação. Os professores tentaram superá-lo com o auxílio do intérprete de Libras. Mas, pela falta de clareza sobre a atuação desse profissional na sala de aula, muitos professores relataram certo mal-estar. Mesmo sabendo da importância e necessidade desse profissional, os registros apontaram que o relacionamento é bastante complexo. A falta de compreensão do papel do intérprete em sala de aula, em algumas situações, é o que motiva essa sensação de mal-estar; porém os docentes foram unânimes em afirmar que esse profissional é imprescindível, tendo em vista não conhecerem a cultura surda e nem possuírem o domínio da Língua Brasileira de Sinais. Também é necessário um relacionamento de parceria entre professor, intérprete e alunos ouvintes, com respeito às diferenças culturais, linguísticas e identidade surda, a fim de que o acadêmico surdo sinta-se incluído no meio onde se encontra e tenha êxito na aprendizagem.

Com esta pesquisa identificou-se a necessidade de programas de capacitação para os docentes dos cursos em que os alunos surdos estão matriculados, com enfoque para a especificidade do processo de ensino e de aprendizagem desse alunado e orientações que facilitem a elaboração de planos de aula. Salienta-se a importância de conhecimento prévio sobre 
REBOLO, Flavinês; MARTINS, Nayara Cesário. Os desafios e as possibilidades do trabalho docente com o aluno surdo na universidade.

a presença do aluno surdo na turma, para que o professor tenha tempo hábil de preparar e readequar suas aulas, a fim de melhor atender esse aluno, em sua disciplina.

O aluno surdo que ingressa na universidade é um sujeito que enfrentou e superou vários desafios ao longo de sua escolaridade e possui saberes que lhe permitiram a entrada na educação superior. Permanecer e concluir o curso superior é um grande desafio para os alunos surdos. A inclusão não é uma tarefa fácil e não é de responsabilidade apenas do professor, mas também da Instituição, que tem um papel fundamental no que diz respeito ao investimento, à implantação de uma cultura inclusiva, ao apoio pedagógico especializado e à realização de formação continuada para os professores, entre outros aspectos. Por isso, deve ser discutida e refletida, para que se encontrem possibilidades de um processo de inclusão não apenas educacional, mas que tenha, também, um alcance para além dos muros escolares, criando oportunidades para a inserção dos surdos em todas as instâncias da vida coletiva.

\section{Referências}

ALBRES, N. de A. Intérprete educacional: políticas e práticas em sala de aula. São Paulo: Harmonia, 2015.

ARANHA, M. S. F. Inclusão social e municipalização. In: MANZINI, E. (Org.). Educação especial: temas atuais. Marília: UNESP/Marília Publicações, 2001. p. 1-9.

BASSO, I. S. Significado e sentido do trabalho docente. Cadernos CEDES, Campinas, v. 19, n. 44, p. 1932, 1998.

BISOL, C. A. et al. Estudantes surdos no ensino superior: reflexões sobre a inclusão. Cadernos de Pesquisa, São Paulo, v. 40, n. 139, p. 147-172, jan./abr. 2010.

BRASIL. Decreto 5.626 de 22 de dezembro de 2005. Regulamenta a Lei no 10.436, de 24 de abril de 2002, que dispõe sobre a Língua Brasileira de Sinais - Libras, e o art. 18 da Lei no 10.098, de 19 de dezembro de 2000. Disponível em: <http://www.planalto.gov.br/ccivil_03/_ato2004-

2006/2005/decreto/d5626.htm>. Acesso em: 12 fev. 2015.

BRASIL. Lei n. 10.436, de 24 de abril de 2002. Dispõe sobre a Língua Brasileira de Sinais - Libras e dá outras providências. Diário Oficial da União, Brasília, 25 abr. 2002.

CARVALHO, G. Responsabilidade Social no Educação Superior: alguns elementos para reflexão.

Estudos: Revista da Associação Brasileira de Mantenedoras de Educação Superior (ABMES), Brasília, v. 23, n. 34, p. 57-74, abr. 2005.

FRANÇA, A. C. L.; RODRIGUES, A. L. Stress e trabalho: guia básico com abordagem psicossomática. São Paulo: Atlas, 1997.

HARRISTON, K. M. P.; NAKASATO, R. Q. Educação universitária: reflexão de inclusão possível. In: LODI, A. C. B.; HARRISTON, K. M. P.; CAMPOS, S. R. L. (Org.). Leitura e escrita no contexto da diversidade. Porto Alegre: Mediação, 2015. p. 65-82. 
REBOLO, Flavinês; MARTINS, Nayara Cesário. Os desafios e as possibilidades do trabalho docente com o aluno surdo na universidade.

KARNOPP, L. B. Língua de sinais e língua portuguesa: em busca de um dialogo. In: LODI, A. C. B. et al. (Org.). Letramento e minorias. Porto Alegre: Mediação, 2013. p. 41-67.

LIMA, C. M. Educação de surdo: desafios para prática e formação de professores. Rio de Janeiro: Ed. Wak, 2015.

LOPES, M. C. Relações de poderes no espaço multicultural da escola para surdos. In: SKLIAR, C. (Org.) A surdez: um olhar sobre as diferenças. Porto Alegre: Mediação, 1998. p. 99-121.

MOURA, M. C. de. O Surdo: caminho para uma nova identidade. Rio de Janeiro: Revinte, 2000.

SANTANA, A. P. A inclusão do surdo no ensino superior no Brasil. Journal of Research in Special Educational Needs, Inglaterra, v. 16, n. 1, p. 85-88, 2016.

SCHÜTZE, F. Análise sociológica e linguística de narrativas. Civitas, Porto Alegre, v. 14, n. 2, p. 11-52, maio/ago. 2014.

SCHÜTZE, F. Proposta de Schütze para análise de narrativas. In: BAUER, M. W.; GASKELL, G.

Pesquisa qualitativa com texto, imagem e som. Petrópolis: Vozes, 2010a. p. 106-107.

SCHÜTZE, F. Pesquisa biográfica e entrevista narrativa. In: WELLER, W.; PFAFF, N. (Org.).

Metodologias qualitativas em educação: teoria e prática. Petrópolis: Vozes, 2010b. p. 210-222.

SILVA, V. Relações sociais de exclusão no âmbito escolar e de trabalho: uma perspectiva de mudança para os surdos na Escola Técnica Federal de Santa Catarina. In: SEMINÁRIO DE PESQUISA EM EDUCAÇÃO DA REGIÃO SUL. Fórum Sul de Coordenadores de Pós-Graduação em Educação/ANPED, 2., 1999. Anais... Curitiba: UFPR/Setor de Educação, 1999. p. 480-495.

STUMPF, M. R. Mudanças estruturais para uma inclusão ética. In: QUADROS, R. M. de (Org.). Estudos surdos III. Petrópolis, RJ: Arara Azul, 2008. p. 14-29.

\author{
Flavinês Rebolo \\ Universidade Católica Dom Bosco - UCDB | Programa de Pós- \\ Graduação em Educação - Mestrado e Doutorado \\ Campo Grande | MS | Brasil. Contato: flavines.rebolo@uol.com.br \\ ORCID 0000-0002-4763-7434
}

Nayara Cesário Martins

Universidade Católica Dom Bosco - UCDB | Núcleo de Apoio

Pedagógico (NAP - UCDB)

Campo Grande | MS | Brasil. Contato: rf68322@ucdb.br

ORCID 0000-0001-8121-9087

Artigo recebido em: 20 ago. 2018 e aprovado em: 16 set. 2018. 